Please do not remove this page

RMIT

UNIVERSITY

\title{
Rheology of a primary and secondary sewage sludge mixture: Dependency on temperature and solid concentration
}

Baroutian, Saeid; Eshtiaghi, Nicky; Gapes, Daniel

https://researchrepository.rmit.edu.au/esploro/outputs/9921861937601341/filesAndLinks?institution=61RMIT_INST\&index=null

Baroutian, S., Eshtiaghi, N., \& Gapes, D. (2013). Rheology of a primary and secondary sewage sludge mixture: Dependency on temperature and solid concentration. Bioresource Technology, 140, 227-233. https://doi.org/10.1016/j.biortech.2013.04.114

Published Version: https://doi.org/10.1016/j.biortech.2013.04.114

Repository homepage: https://researchrepository.rmit.edu.au

(C) 2013 Elsevier Ltd. All rights reserved

Downloaded On 2023/04/26 18:18:08 +1000 
Thank you for downloading this document from the RMIT Research Repository.

The RMIT Research Repository is an open access database showcasing the research outputs of RMIT University researchers.

RMIT Research Repository: http://researchbank.rmit.edu.au/

\section{Citation:}

Baroutian, S, Eshtiaghi, N and Gapes, D 2013, 'Rheology of a primary and secondary sewage sludge mixture: Dependency on temperature and solid concentration', Bioresource Technology, vol. 140, pp. 227-233.

See this record in the RMIT Research Repository at:

http://researchbank.rmit.edu.au/view/rmit:21225

Version: Accepted Manuscript

Copyright Statement: @ 2013 Elsevier Ltd. All rights reserved

Link to Published Version:

http://dx.doi.org/10.1016/j.biortech.2013.04.114 


\title{
Rheology of a Primary and Secondary Sewage Sludge Mixture: Dependency on Temperature and Solid Concentration
}

\author{
Saeid Baroutian ${ }^{1,}$, , Nicky Eshtiaghi ${ }^{2}$, Daniel J. Gapes ${ }^{1}$

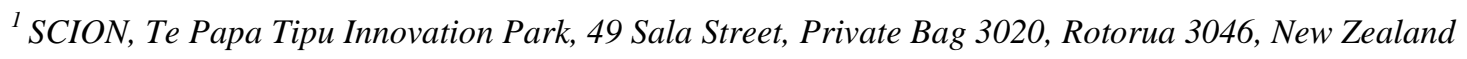 \\ ${ }^{2}$ Rheology and Materials Processing Centre, Dept. of Chemical Engineering, RMIT University, Victoria 3001, \\ Australia
}

\begin{abstract}
The main objective of this study was to investigate the rheology of mixed primary and secondary sludge and its dependency on solid content and temperature. Results of this study showed that the temperature and solid concentration are critical parameters affecting the mixed sludge rheology. It was found that the yield stress increases with an increase in the sludge solid content and decreases with increasing temperature. The rheological behaviour of sludges was modelled using the Herschel-Bulkley model. The results of the model showed a good agreement with experimental data. Depending on the total solid content, the average error varied between 3.25 to $6.22 \%$.
\end{abstract}

Keyword: Rheology, municipal wastewater sludge, solid concentration, yield stress, temperature

Corresponding author: Tel.: +64-7-3435436, Email Address: Saeid.Baroutian@ scionresearch.com 


\section{Introduction}

Sewage sludge, the solid residue of municipal wastewater treatment process, is a mixture of about $20 \%$ solids and $80 \%$ liquid part. The treated liquor is released directly to aqueous environment while solids are removed for disposal or pumped to sludge treatment line. There are three main types of sewage sludges: primary or raw, secondary and anaerobically digested sludges. Primary sludge contains the solid separated from sewage flowing to a wastewater treatment plant. Secondary sewage sludge contains solid and micro-organisms which are produced within the treatment plant. Digested sludge is a form of primary and secondary solids, stabilised through anaerobic fermentation.

Sewage sludge is a complex material and particularly difficult to characterise (Seyssiecq et al., 2003). It can be generally described as a water-based suspension containing suspended particles, fibrous material and dissolved substances. The characteristics of the sewage sludge vary depending on the wastewater source, treatment process, chemical additives like polymers and mechanical operations like thickening. All these factors will influence the fluid behaviour and sludge handling (Koseoglu et al., 2012; Seyssiecq et al., 2003).

The safe, efficient and economical transfer of sewage sludge in wastewater treatment plants and in sludge treatment facilities is of great importance. For that reason, mechanical and fluid dynamic characteristics of sludge must be determined. These rheological characteristics are essential in the design of different industrial processes due to their importance in heat and mass transfer calculations (Bandrés et al., 2009). They are also important in sewage sludge management, not only as designing parameters in transporting, storing, landfilling and spreading operations, but also as controlling parameter in many treatments, such as stabilisation and dewatering (Lotito et al., 1997). Appropriate treatment of wastewater as a result of an efficient 
design would help in environment protection and preservation (Asadi et al., 2012). Design and operation of wastewater treatment plants benefit from accurate knowledge of the hydrodynamic functioning of the associated plant such as pumps, heat exchangers and operations. .Accurate prediction of the flow behaviour of these engineering hydrodynamic processes requires the rheological characteristics of the sludge as input (Baudez et al., 2011; Eshtiaghi et al., 2012). Basically, rheology of municipal sludge is defined by its viscous characteristics which can be determined by the relationship between shear rate and shear stress. Sewage sludges are nonNewtonian fluids, because the shear rate or the velocity gradient is not linearly proportional to the shear stress (Dentel, 1997). This leads to difficulty in the rheological characterisation due to the fact that sewage sludge is a complex material and its rheological properties of cannot be related to a single value of its viscosity (Seyssiecq et al., 2003). The rheological properties are highly correlated with structural and surface characteristics of bioaggregates (Li \& Yu, 2011). A variety of methods and devices have been used to measure the rheological characteristics of sewage sludges. These have ranged from capillary rheometers (Behn, 1962; Slatter, 1997) to rotational rheometers (Abu-Orf \& Dentel, 1997; Baudez et al., 2011; Behn, 1962; Forster, 1982; Lotito et al., 1997; Mori et al., 2006; Tixier et al., 2003). Each type provides slightly different information and has different advantages and disadvantages and there does not appear to be any clear-cut criterion for choosing which type is better or more appropriate (Forster, 2002). As stated before, sewage sludge rheology has been widely measured but most of the literature has concentrated on secondary or digested sludges alone. Moeller and Torres characterised rheological behaviour of primary and secondary sludges and correlate it with physico-chemical sludge properties (Moeller \& Torres, 1997). There is no information available on rheological properties of mixed primary and secondary sludge. There is also very little information in the 
literature about the impact of temperature on sludge rheology. Baudez et al. (Baudez et al., 2013b) studied the impact of temperature on the rheological behaviour of anaerobically digested sludge. They found that both solid and liquid rheological characteristics decrease with temperature. Baudez et al. (Baudez et al., 2013a) also found that the decrease of viscoelastic properties is proportional to the decrease of water viscosity with increase in temperature due to the effect of thermal motion. Manoliadis and Bishop investigate the effect of temperature on the rheological properties of sewage sludge and observed a significant influence of temperature on the viscosity of sludges (Manoliadis \& Bishop, 1984).

From a theoretical point of view, a wide variety of models have been presented in literature to describe rheological behaviour of sewage sludges. Most of the rheological models are based on a simple power-law equation, the so called Ostwald model (Behn, 1962; Lotito et al., 1997). The other most common models are the Bingham model (Khalili Garakani et al., 2011; Sozanski et al., 1997), the Herschele-Bulkley model (Eshtiaghi et al., 2012; Slatter, 2008) and the Sisko model (Baudez, 2008). The Herschel-Bulkley model is able to describe the sludge behaviour under rest and flow conditions, the pseudoplastic, or shear-thinning as well as the yield stress characteristics.

The current study aimed to characterise the mixture of primary and secondary sewage sludge taken from a wastewater treatment plant and investigate the effects of temperature and solid content. This provides useful information on the rheological behaviour of the mixed sludge for optimisation and design of sludge processing facilities. The sludge behaviour was fitted and described using the Herschele-Bulkley model. 


\section{Methodology}

\subsection{Sludge sample}

The sludge samples were a mixture of primary and secondary sludges obtained from Rotorua District Council wastewater treatment plant, Rotorua, New Zealand. The treatment plant provides preliminary (screening and grit removal), primary (sedimentation, concentration and fermentation), and secondary (anaerobic fermentation, de-nitrification, aeration and clarification) treatment of wastewater. Sludge from primary treatment and secondary treatment is dewatered using filter belt presses to reduce sludge weight and make it easier to handle. This plant produces 25 ton of sludge per day including primary and secondary sludges.

In this work the mixed sludge, which consisted of $40 \%$ primary and $60 \%$ secondary sludges, were diluted with tap water to total solid contents of 4.3, 4.5, 4.9, 7.3 and $9.8 \%$. The total solid contents of the samples were obtained by means of the gravimetric method.

\subsection{Sludge characterisation}

The composition of the mixed sludge were determined using ${ }^{13} \mathrm{C}$ Nuclear Magnetic Resonance (The Bruker Avance-400 NMR spectrometer, Germany). Solid/liquid state 13C -NMR is an established semi-quantitative analytical technology for structural elucidation of compounds and requires no sample preparation.

Elemental composition analysis was also conducted for the sludge using an Atomic Absorption Spectrometer (Varian Spectra AA 220FS).

\subsection{Rheology measurement}


A controlled stress rheometer (Advanced Rheometer AR2000, TA Instruments Ltd) was used to measure rheology of the sludge samples. The rheometer was fitted with a stainless steel parallel plates geometry (60 mm diameter, $500 \mu \mathrm{m}$ gap). Prior to measurements, a constant shear stress was first imposed in order to pre-shear the sludge. Followed by the conditioning step, the flow step was carried out by applying different shear ranging from 10 to $1000 \mathrm{~s}^{-1}$ using a logarithmic ramp, in order to decrease the initial acceleration and the effects due to instrument inertia. The variations in torque behaviour around one complete revolution of the driver shaft was mapped and used for subsequent real-time corrections in the tests.

The flow curve measurements were performed at temperatures between $298.15 \mathrm{~K}$ and $328.15 \mathrm{~K}$. The temperature control system used a Peltier Plate which provides temperature accuracy of \pm $0.1 \mathrm{~K}$ and a typical heating rate of $293.15 \mathrm{~K} / \mathrm{min}$. It is configured for parallel plates geometry with rapid conduction of heat to the sample.

\subsection{Rheological modelling}

Sludges are mainly composed of water and the remaining part is made of organic matter and bacteria which tend to aggregate forming flocs (Baudez et al., 2013a). Lower concentration of sludges can be modelled as a Newtonian fluid. For Newtonian fluid, shear stress $(\tau)$ is linearly related to the shear rate $(\dot{\gamma})$ :

$\tau=\mu \dot{\gamma}$

where, $\mu$ is the viscosity which is independent of the shear rate and initial stress (yield stress) at a given temperature and pressure. With higher concentration of solids, the sludge behaves as 
Bingham plastic (Frost \& Ovens, 1982; Guibaud et al., 2003; Sozanski et al., 1997) or Ostwald pseudoplastic (Valioulis, 1980). Pseudoplastic behaviour can be represented by Ostwald model (Behn, 1962; Lotito et al., 1997; Seyssiecq et al., 2003):

$\tau=k \dot{\gamma}^{n}$

The Ostwald model is one of the most commonly used equations to represent the non-Newtonian behaviour of sewage sludges. However the model can only be used when modelling the shearthinning zone of the rheogram of sludge suspensions, i.e. in an intermediate range of shear rates (Mori et al., 2006).

Geinopolos and Katz (Geinopolos \& Kaiz, 1964) applied the Bingham plastic model for primary, secondary and digested sludges and suggested the sludges behave like plastic material:

$\tau=m \dot{\gamma}+\tau_{y}$

where $\tau_{y}$ is the yield stress. Viscosity-type coefficient, $m$, is apparent viscosity correlated to the shear stress/shear rate ratio.

The non-Newtonian fluid behaviour of sludges can be described by the Herschel-Bulkley model. This model was introduced by Herschel and Bulkley in 1926 and allows studying the rheograms on the complete range of shear rates investigated:

$\tau=k \dot{\gamma}^{n}+\tau_{y}$ 
where $k$ and $n$ are regarded as model factors.

The abilities of the Bingham (Eq. 3) and Herschel-Bulkley (Eq. 4) models to show the sludge behaviour before flow occurs (very low shear stress), and when it begins to flow (shear stresses exceeding the yield) make these yield stress models more preferable. However, Bingham model is not efficient in describing the overall rheological profile of sludges, especially at higher solid content. The Herschel-Bulkley model involves more adjustable parameter and replaces the plastic viscosity term in the Bingham model with a power law expression. This enables the model to describe the pseudoplastic, or shear-thinning characteristics of sludge as well as the yield stress.

Since the Herschel-Bulkley model is more efficient in describing the sludge rheological behaviour, especially in the upper or lower Newtonian region as well as the power law region, this model was tested against the experimental data generated in this work. In particular, individual temperature and solid concentration experiments were fitted using the HerschelBulkley model (Eq. 4), yielding multiple yield stress, $\tau_{y}$, and Herschel-Bulkley coefficients, $k$ and $n$. The correlation was carried out over the temperature range $298.15-328.15 \mathrm{~K}$ and total solid contents 4.3-9.8\%. The broad context of this work is to provide an improved mechanistic understanding of the rheology of a mixture of primary and secondary sludges.

\subsection{Statistical assessment}

In this study, to assess the Herschel-Bulkley model in terms of predictive capability and to know the extent to which it can be used with better prediction quality of the mixed sludge rheology, several statistical descriptors were calculated and their values compared. The statistical descriptors are the Index of Agreement (IA) showing the overall accuracy of the model, 
Fractional Bias (FB) measuring tendency of the model towards over or under-prediction, Normalised Mean Square Error (NMSE) showing the overall accuracy of the model, Variance of Geometric (VG) indicating systematic and random errors, Geometric Mean Bias (MG)

identifying systematic errors and Regression Coefficient $\left(\mathrm{R}^{2}\right)$ describing the association between measured shear stress and predicted results. The calculation expressions for these descriptors are given below:

$I A=1-\frac{\sum_{i=1}^{N}\left(P_{i}-E_{i}\right)^{2}}{\sum_{i=1}^{N}\left(\left|P_{i}-\bar{E}\right|+\left|E_{i}-\bar{E}\right|\right)^{2}}$

$F B=\frac{\bar{E}-\bar{P}}{0.5(\bar{E}+\bar{P})}$

$N M S E=\frac{\overline{(E-P)^{2}}}{\overline{E P}}$

$M G=\exp (\overline{\ln \mathrm{E}}-\overline{\ln \mathrm{P}})$

$V G=\exp \overline{\left[(\ln E-\ln P)^{2}\right]}$

where $E, P, \bar{E}$ and $\bar{P}$ are experimentally measured shear stress, predicted shear stress, average of the entire experimental data set and average of the entire prediction data set, respectively.

\section{Results and discussion}

\subsection{Sludge characterisation}

The NMR analysis showed that protein was the dominant constituent in the sludge. The carbohydrates were the second largest group of material found in the sludge. These 
carbohydrates consisted in a large part of cellulose, which most likely originated from tissue paper.

Elemental composition analysis showed that carbon and oxygen are the dominant elements. The compositions of sludge used in this study are shown in Figure 1 which is typical of the Rotorua District Council wastewater treatment sludge.

\subsection{Rheology measurement}

With the purpose of meeting the laboratory safety requirements, the sludges were sterilised at $110^{\circ} \mathrm{C}$ for $20 \mathrm{~min}$. To confirm that sterilisation has no significant impact on the sludge rheology, shear stress was measured at different shear rates and temperature for the sterilised sludge with $4.3 \%$ total solid content. As can be seen in Table 1, comparison between the viscosities of sterilised and un-sterilised sludges revealed that sludge viscosity changes slightly by autoclaving the material. Since the average absolute percent change is low $(6.99 \%)$ therefore in general the effect of sterilisation can be neglected. The average absolute change in viscosity at higher shear rates $\left(500\right.$ to $\left.1000 \mathrm{~s}^{-1}\right)$ was even lower $(4.20 \%)$. This means for shear rates within the range of pumping or mixing the above assumption is more valid.

The flow curves for the mixed sludges with 4.3 to $9.8 \%$ solid concentration at temperatures ranging from 298.15 to $328.15 \mathrm{~K}$ are presented in Figure 2. The results revealed that shear stress increases non-linearly with increase in shear rate and decreases with increase in temperature. When the sludges are heated, the cohesive forces between the molecules reduce due to thermal motion which eventually reduces the shear stress and thus the viscosity of the fluid. Dependency of shear stress on solid content is also illustrated in Figure 2. The figure shows that shear stress increases with increase in the sludge solid content. This increase in shear stress with 
solid content was more obvious at higher shear rates. It is known that superficial groups including proteins and polysaccharides are responsible for the rheological behaviour of sludge (Forster, 1982). As the sludge polysaccharide and protein content is increased (with increase in solid content), the shear stress and viscosity of the sludge also increased as evidence here.

\subsection{Rheological modelling}

Solid concentration was found to be a critical parameter in detrmining the rheological characteristics of mixed sludge. Many authors have shown that the solid content is one of the main parameters affecting the sludge rheology (Guibaud et al., 2003; Monteiro, 1997; Seyssiecq et al., 2003; Slatter, 1997). Experimental results showed that temperature has significant effect on the sludge rheology. The results of the Herschel-Bulkley model are shown together with experimental data in Figure 2. A reasonably good agreement was observed between the model output and the experimental data. Depending on the total solid content and temperature, the average error varied between 3.25 to $6.22 \%$ and 4.23 to $5.06 \%$, respectively.

As described earlier, the Herschel-Bulkley model has the advantage of taking into account yield stress $\left(\tau_{y}\right)$. This term quantifies the amount of stress that the fluid may experience before it yields and begins to flow. The mechanistic explanation for this behaviour is the chemical interaction and physical forces between the sludge particles or large molecules which create a weak solid structure. To break this structure and produce flow, a certain amount of stress is required to. Once the structure has been broken, the particles move with the liquid under viscous forces (Eshtiaghi et al., 2012). The data presented in Figure 3 shows the dependency of the mixed sludge yield stress on the solid concentration and temperature. As can be seen, yield stress 
is in linear relationship with solid concentration and exponential with the inverse of temperature. The yield stress increases with increase in solid concentration and decrease in temperature. The dependency of the Herschel-Bulkley model coefficients on temperature is presented in Figure 4. As can be seen the coefficient $k$ is in linear relationship with temperature. The power law coefficient, $n$, was kept constant within the temperature range in order to obtain a better fit. In addition, coefficients $k$ and $n$, were found to be in logarithmic and power law relationship with total solid content, respectively.

\subsection{Statistical assessment}

The results of statistical assessment are summarised in Table 2. A good agreement between the model and experimental results was achieved across all the total solid contents considered (IA between 9.785E-01 and 9.993E-01). Comparison indicates that prediction overestimation improves with increase in the sludges solid content. The highest overall accuracy in terms of normalised mean square error (NMSE) was achieved for the sludge with highest total solid content (1.354E-03). A non-significant normalised mean square error for all the sludges confirms reasonable accuracy of the model. The values of geometric variance (VG) and geometric mean bias (MG) revealed that the model was successful to predict shear stress at different condition for different solid contents in terms of systematic and random errors.

\section{Conclusion}

It is important to identify the dominating rheological characteristics of mixture of primary and secondary sludges in order to improve and to understand the transport and treatment processes. 
This study investigated the rheological behaviour of this mixture. The Herschel-Bulkley model was used to describe the rheological behaviour and the model was in a reasonable agreement with experimental data. Concentration and temperature were found to have a significant impact on the sludge yield stress and the model coefficients $(k$ and $n)$. It can be concluded that the mixture of sludges exhibited a strong dependence on solid content and temperature.

\section{Acknowledgment}

The authors thank Scion (New Zealand Forest Research Institute) for the Postdoctoral Fellowship and Rotorua District Council for their support.

\section{References}

1. Abu-Orf, M.M., Dentel, S.K. 1997. Effect of mixing on the rheological characteristics of conditioned sludge: full scale studies. Water Science and Technology, 36(11), 51-60.

2. Asadi, A., Zinatizadeh, A.A.L., Hasnain Isa, M. 2012. Performance of intermittently aerated up-flow sludge bed reactor and sequencing batch reactor treating industrial estate wastewater: A comparative study. Bioresource Technology, 123(0), 495-506.

3. Bandrés, I., Giner, I., Aldea, M.E., Cea, P., Lafuente, C. 2009. Experimental and predicted viscosities of binary mixtures of cyclic ethers with 1-chloropentane or 1-chlorohexane at 283.15, 298.15, and 313.15 K. Thermochimica Acta, 484(1-2), 22-26.

4. Baudez, J.-C. 2008. Physical aging and thixotropy in sludge rheology. Applied Rheology, 18(1), 13459-13466. 
5. Baudez, J.-C., Gupta, R.K., Eshtiaghi, N., Slatter, P. 2013a. The viscoelastic behaviour of raw and anaerobic digested sludge: Strong similarities with soft-glassy materials. Water Research, 47(1), 173-180.

6. Baudez, J.C., Markis, F., Eshtiaghi, N., Slatter, P. 2011. The rheological behaviour of anaerobic digested sludge. Water Research, 45(17), 5675-5680.

7. Baudez, J.C., Slatter, P., Eshtiaghi, N. 2013b. The impact of temperature on the rheological behaviour of anaerobic digested sludge. Chemical Engineering Journal, 215-216(0), 182187.

8. Behn, V.C. 1962. Experimental Determination of Sludge-Flow Parameters. Journal of the Sanitary Engineering Divisio, 88(3), 39-54.

9. Dentel, S.K. 1997. Evaluation and role of rheological properties in sludge management. Water Science and Technology, 36(11), 1-8.

10. Eshtiaghi, N., Yap, S.D., Markis, F., Baudez, J.-C., Slatter, P. 2012. Clear model fluids to emulate the rheological properties of thickened digested sludge. Water Research, 46(9), 3014-3022.

11. Forster, C.F. 2002. The rheological and physico-chemical characteristics of sewage sludges. Enzyme and Microbial Technology, 30(3), 340-345.

12. Forster, C.F. 1982. SLUDGE SURFACES AND THEIR RELATION TO THE RHEOLOGY OF SEWAGE SLUDGE SUSPENSIONS. Journal of chemical technology and biotechnology, 32(8), 799-807.

13. Frost, R.C., Ovens, J.A. 1982. A method of estimating viscosity and designing pumping systems for lickened sludges. in: 8th nternational Conference On The Hydraulic Transport Of Solids In Pipes. Johanesburg, South Africa, pp. 485-501. 
14. Geinopolos, A., Kaiz, W.I. 1964. Study of the rotating cylinder sludge collector in the dissolved air notation process. Journal of the Water Pollution Control Federation, 36(6), 712.

15. Guibaud, G., Dollet, P., Tixier, N., Dagot, C., Baudu, M. 2003. Characterisation of the evolution of activated sludges using rheological measurements. Process Biochemistry, 39(11), 1803-1810.

16. Khalili Garakani, A.H., Mostoufi, N., Sadeghi, F., Hosseinzadeh, M., gt, Fatourechi, H., Sarrafzadeh, M.H., Mehrnia, M.R. 2011. COMPARISON BETWEEN DIFFERENT MODELS FOR RHEOLOGICAL CHARACTERIZATION OF ACTIVATED SLUDGE. Iranian Journal of Environmental Health Science \&amp; Engineering, 8(3), 255-264.

17. Koseoglu, H., Yigit, N.O., Civelekoglu, G., Harman, B.I., Kitis, M. 2012. Effects of chemical additives on filtration and rheological characteristics of MBR sludge. Bioresource Technology, 117(0), 48-54.

18. Li, W.-W., Yu, H.-Q. 2011. Physicochemical characteristics of anaerobic H2-producing granular sludge. Bioresource Technology, 102(18), 8653-8660.

19. Lotito, V., Spinosa, L., Mininni, G., Antonacci, R. 1997. The rheology of sewage sludge at different steps of treatment. Water Science and Technology, 36(11), 79-85.

20. Manoliadis, O., Bishop, P.L. 1984. Temperature Effect on Rheology of Sludges. Journal of Environmental Engineering, 110(1), 286-290.

21. Moeller, G., Torres, L.G. 1997. Rheological characterization of primary and secondary sludges treated by both aerobic and anaerobic digestion. Bioresource Technology, 61(3), 207-211. 
22. Monteiro, P.S. 1997. The influence of the anaerobic digestion process on the sewage sludges rheological behaviour. Water Science and Technology, 36(11), 61-67.

23. Mori, M., Seyssiecq, I., Roche, N. 2006. Rheological measurements of sewage sludge for various solids concentrations and geometry. Process Biochemistry, 41(7), 1656-1662.

24. Seyssiecq, I., Ferrasse, J.-H., Roche, N. 2003. State-of-the-art: rheological characterisation of wastewater treatment sludge. Biochemical Engineering Journal, 16(1), 41-56.

25. Slatter, P. 2008. Pipe flow of highly concentrated sludge. Journal of Environmental Science and Health, Part A, 43(13), 1516-1520.

26. Slatter, P.T. 1997. The rhological characterization of sludges. Water Science and Technology, 36(11), 9-18.

27. Sozanski, M.M., Kempa, E.S., Grocholski, K., Bien, J. 1997. The rheological experiment in sludge properties research. Water Science and Technology, 36(11), 69-78.

28. Tixier, N., Guibaud, G., Baudu, M. 2003. Determination of some rheological parameters for the characterization of activated sludge. Bioresource Technology, 90(2), 215-220.

29. Valioulis, A. 1980. Relationship between settling, dewatering and rheological properties of activated sludges, Vol. Master, Comell Univ. Ithaca. 


\section{Figure captions}

Figure 1. Elemental and solid state NMR composition analyses for Rotorua District Council mixed sludge

Figure 2. Figure 2. Flow curves of sludges with different total solid contents at various temperatures

(a) $4.3 \% \mathrm{TS}$; (b) $4.5 \% \mathrm{TS}$; (c) $4.9 \% \mathrm{TS}$; (d) $7.3 \% \mathrm{TS}$; (e) $9.8 \% \mathrm{TS}$

Figure 3. Evaluation of the yield stress with (a) total solid content and (b) temperature for the mixed sludge system

Figure 4. Evaluation of the Herschel-Bulkley parameters with temperature for the mixed sludge system 


\section{Table titles}

Table 1. Comparison between the viscosities of sterilised and un-sterilised sludges with $4.3 \%$ total solids at different shear rates and temperatures

Table 2. Summary of model statistical assessment 
Table 1. Comparison between the viscosities of sterilised and un-sterilised sludges with $4.3 \%$ total solids at different shear rates and temperatures

\begin{tabular}{cccccccc}
\hline \multicolumn{7}{c}{ Shear rate } & \multicolumn{7}{c}{ Absolute difference in viscosity (\%) } \\
$(1 / \mathrm{s})$ & 298.15 & 303.15 & 308.15 & 313.15 & 318.15 & 323.15 & 328.15 \\
& $\mathrm{~K}$ & $\mathrm{~K}$ & $\mathrm{~K}$ & $\mathrm{~K}$ & $\mathrm{~K}$ & $\mathrm{~K}$ & $\mathrm{~K}$ \\
\hline 10.00 & 10.94 & 11.48 & 10.09 & 8.76 & 8.21 & 5.38 & 4.08 \\
12.59 & 7.95 & 8.31 & 7.41 & 6.31 & 5.49 & 2.58 & 1.82 \\
15.85 & 10.28 & 10.73 & 6.05 & 5.15 & 4.11 & 1.16 & 1.41 \\
19.96 & 7.59 & 7.89 & 7.29 & 6.22 & 5.35 & 2.43 & 3.50 \\
25.12 & 7.81 & 8.12 & 8.30 & 7.14 & 6.38 & 3.49 & 5.40 \\
31.63 & 7.80 & 8.12 & 8.29 & 7.13 & 6.37 & 3.48 & 4.72 \\
39.82 & 7.97 & 8.30 & 9.15 & 7.92 & 7.24 & 4.38 & 7.61 \\
50.13 & 9.23 & 9.64 & 10.54 & 9.24 & 8.66 & 5.84 & 6.56 \\
63.11 & 10.68 & 11.14 & 12.13 & 10.79 & 10.20 & 7.43 & 7.56 \\
79.45 & 12.30 & 12.71 & 14.11 & 12.85 & 12.25 & 9.54 & 11.27 \\
100.00 & 12.94 & 13.33 & 13.27 & 11.99 & 11.40 & 8.67 & 7.91 \\
125.90 & 11.92 & 12.33 & 11.74 & 10.46 & 9.86 & 7.08 & 6.32 \\
158.50 & 13.68 & 12.76 & 9.33 & 8.12 & 7.40 & 4.54 & 4.42 \\
199.60 & 7.82 & 8.05 & 9.34 & 8.18 & 7.46 & 4.61 & 4.20 \\
251.20 & 10.55 & 10.87 & 9.93 & 8.77 & 8.10 & 5.26 & 7.12 \\
316.30 & 8.16 & 6.86 & 9.63 & 8.47 & 7.81 & 4.96 & 6.65 \\
398.20 & 6.24 & 4.20 & 8.66 & 9.91 & 9.32 & 6.53 & 5.74 \\
501.30 & 3.81 & 2.58 & 9.78 & 8.63 & 7.96 & 5.12 & 4.34 \\
631.10 & 4.29 & 2.42 & 4.91 & 6.76 & 5.90 & 2.00 & 2.17 \\
794.50 & 3.23 & 2.93 & 3.61 & 6.99 & 5.95 & 2.05 & 3.71 \\
1000.00 & 3.36 & 3.15 & 3.85 & 2.86 & 2.63 & 2.76 & 2.07 \\
\hline
\end{tabular}


Table 2. Summary of model statistical assessment

\begin{tabular}{llllll}
\hline TS & IA & FB & NMSE & MG & VG \\
$(\%)$ & $(1.000 \mathrm{E}+00)^{a}$ & $(0.000 \mathrm{E}+00)^{a}$ & $(0.000 \mathrm{E}+00)^{a}$ & $(1.000 \mathrm{E}+00)^{a}$ & $(1.000 \mathrm{E}+00)^{a}$ \\
\hline 4.3 & $9.785 \mathrm{E}-01$ & $5.383 \mathrm{E}-03$ & $3.439 \mathrm{E}-03$ & $1.005 \mathrm{E}+00$ & $1.003 \mathrm{E}+00$ \\
4.5 & $9.923 \mathrm{E}-01$ & $3.402 \mathrm{E}-03$ & $2.305 \mathrm{E}-03$ & $1.004 \mathrm{E}+00$ & $1.003 \mathrm{E}+00$ \\
4.9 & $9.921 \mathrm{E}-01$ & $3.421 \mathrm{E}-03$ & $5.512 \mathrm{E}-03$ & $1.008 \mathrm{E}+00$ & $1.006 \mathrm{E}+00$ \\
7.3 & $9.981 \mathrm{E}-01$ & $2.271 \mathrm{E}-03$ & $3.258 \mathrm{E}-03$ & $1.005 \mathrm{E}+00$ & $1.003 \mathrm{E}+00$ \\
9.8 & $9.993 \mathrm{E}-01$ & $1.832 \mathrm{E}-03$ & $1.354 \mathrm{E}-03$ & $1.002 \mathrm{E}+00$ & $1.001 \mathrm{E}+00$ \\
\hline
\end{tabular}

${ }^{a}$ Figures in brackets are ideal values 


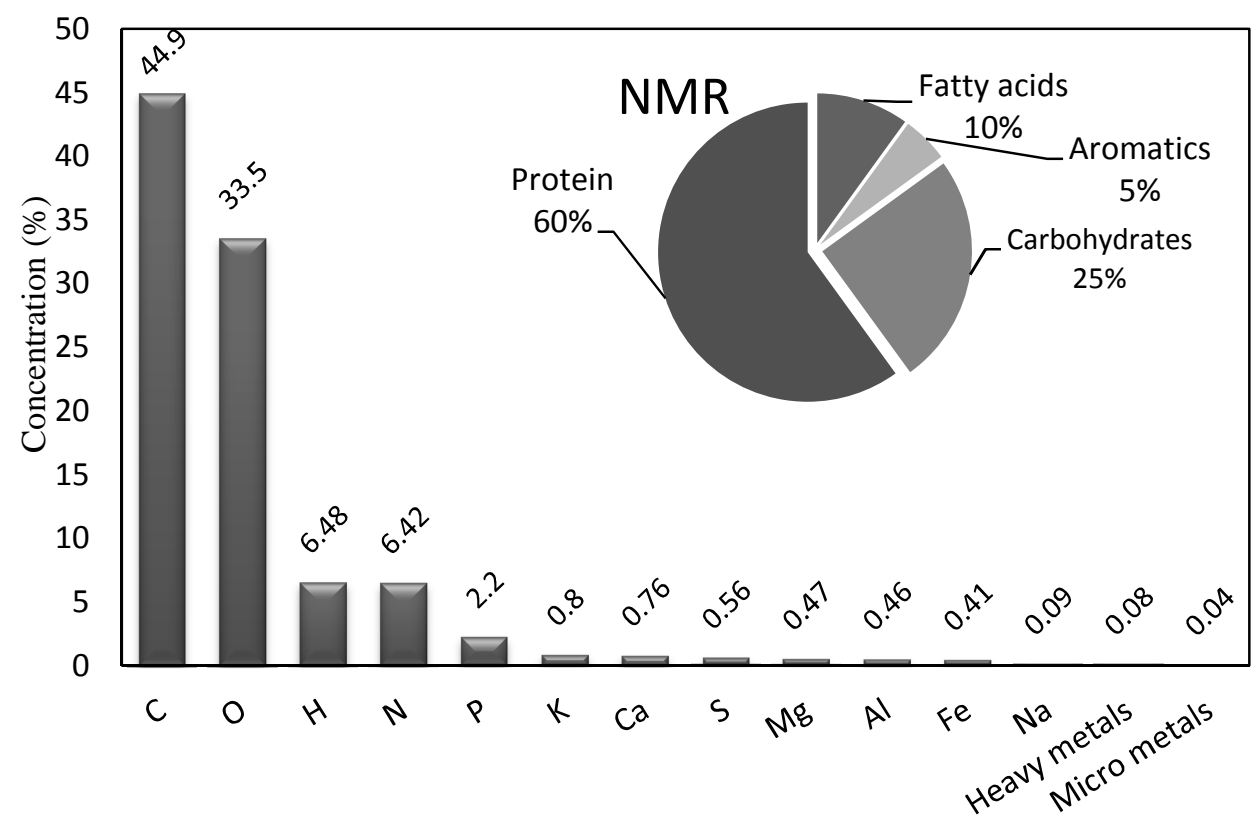

Figure 1. Elemental and solid state NMR composition analyses for Rotorua District Council mixed sludge 

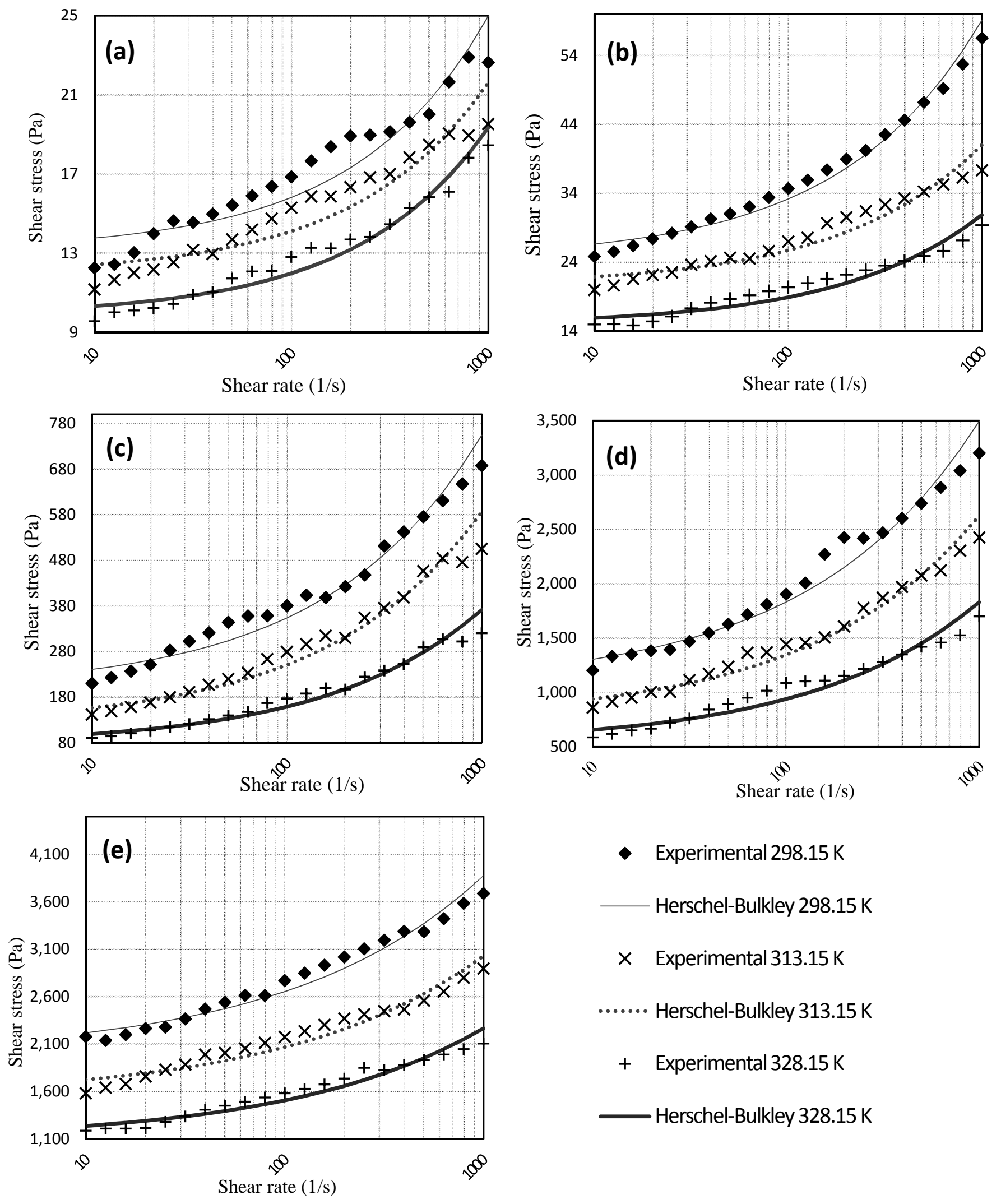

- Experimental $298.15 \mathrm{~K}$

- Herschel-Bulkley $298.15 \mathrm{~K}$

$\times \quad$ Experimental $313.15 \mathrm{~K}$

Herschel-Bulkley 313.15 K

+ Experimental $328.15 \mathrm{~K}$

- Herschel-Bulkley 328.15 K

Figure 2. Flow curves of sludges with different total solid contents at various temperatures (a) $4.3 \% \mathrm{TS}$; (b) $4.5 \% \mathrm{TS}$; (c) $4.9 \% \mathrm{TS}$; (d) $7.3 \% \mathrm{TS}$; (e) $9.8 \% \mathrm{TS}$ 

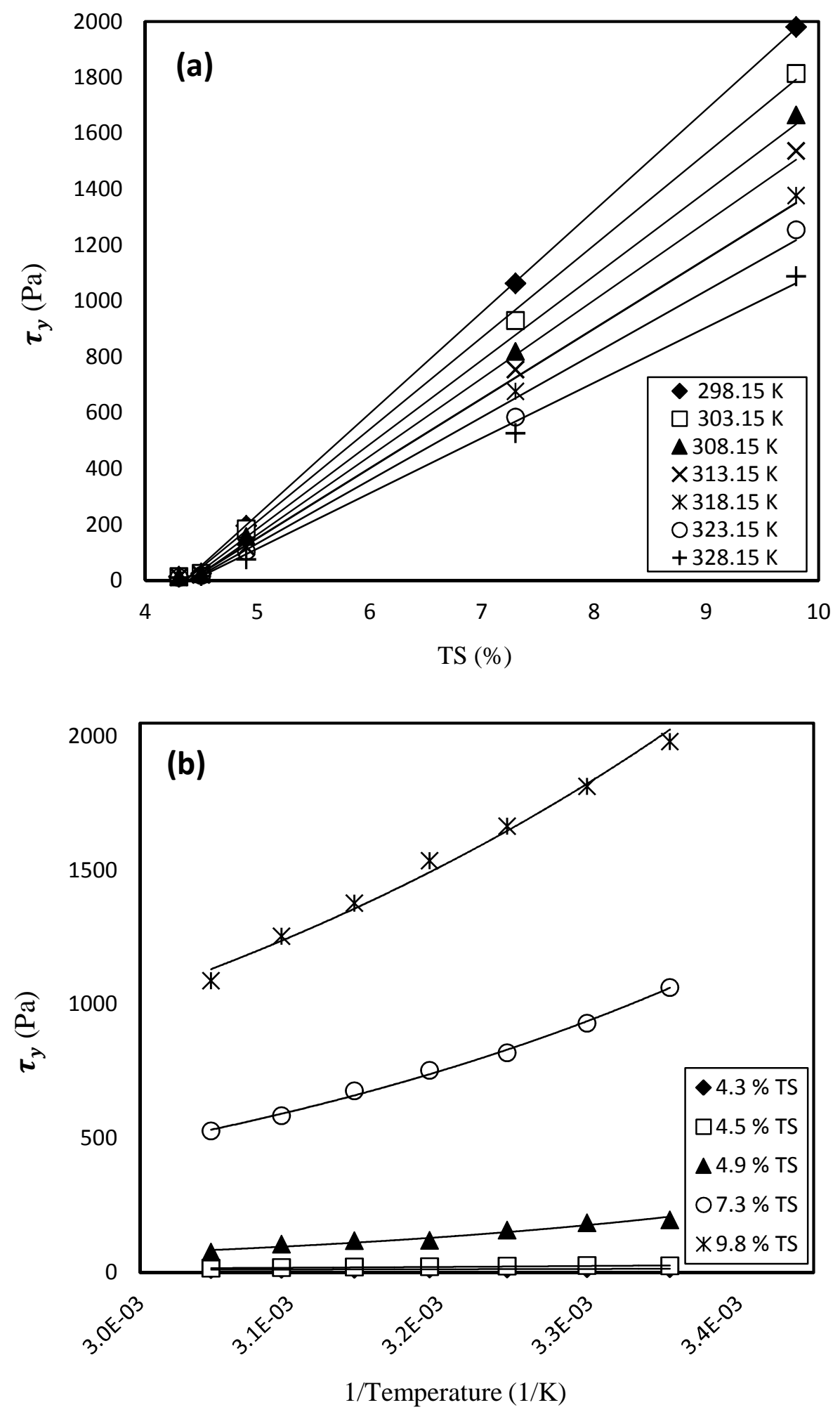

Figure 3. Evaluation of the yield stress with (a) total solid content and (b) temperature for the mixed sludge system 

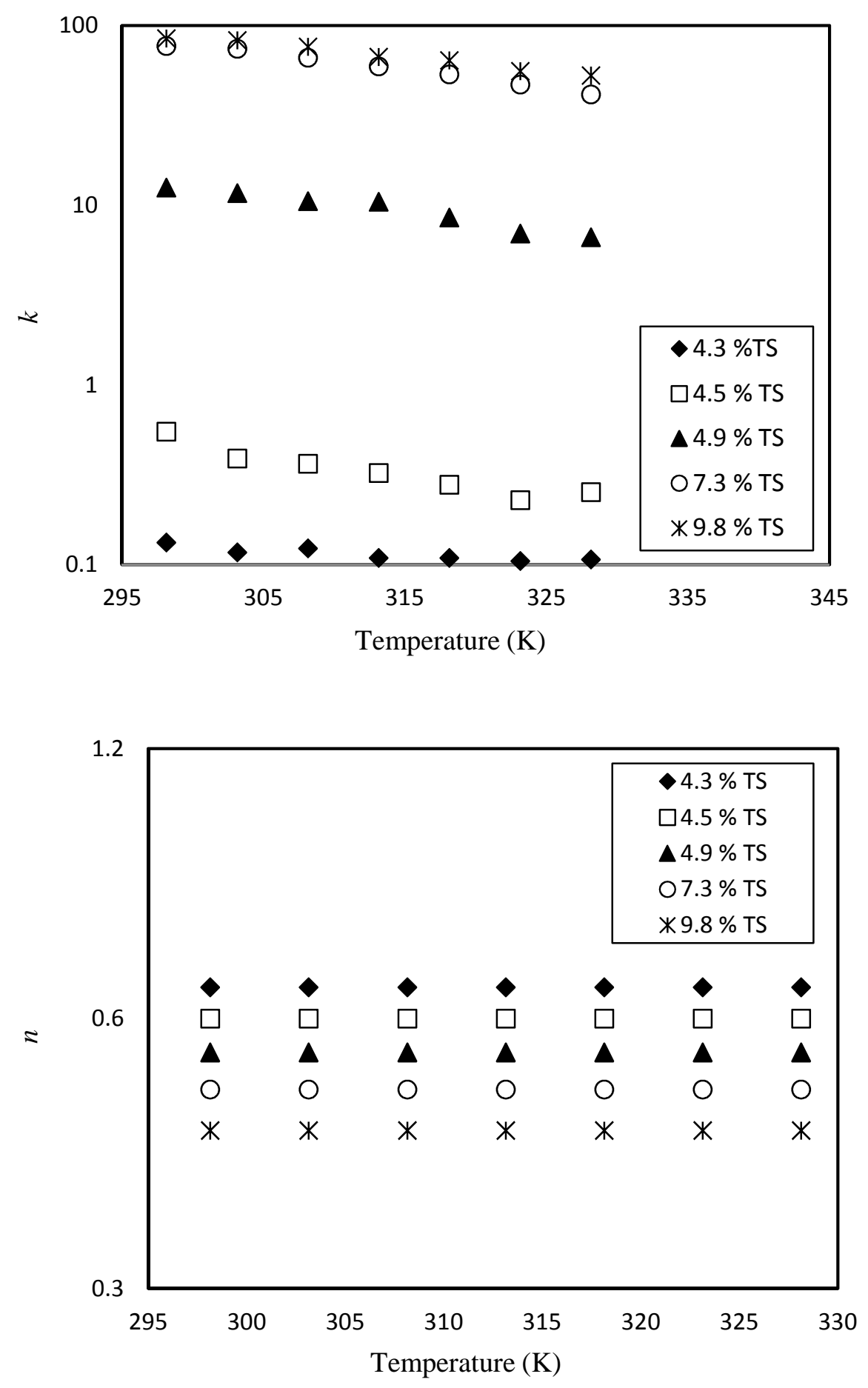

Figure 4. Evaluation of the Herschel-Bulkley parameters with temperature for the mixed sludge system 